\title{
Crassabwa : a new genus of small minnow mayflies (Ephemeroptera : Baetidae) from Africa
}

\author{
C. R. Lugo-Ortiz 1 \\ W. P. McCafferty 1
}

Keywords : Ephemeroptera, Baetidae, Crassabiwa badia, C. flava, C. lowede, C. vitrea, new genus, new combinations, Africa.

Crassabwa Lugo-Ortiz \& McCafferty (Ephemeroptera : Baetidae); $n$. gen., is erected for a small monophyletic group of distinctive Afrotropical species previously assigned to Afroptilum Gillies and Centroptilum Eaton, including C. badia (Kopelke), $\mathrm{n}$. comb., C. flava (Crass), n. comb. (type species), C. loweae (Kimmins), n comb., and C. vitrea (Navás), n. comb. Larvae of Crassabwa are distinguished by possesșing a thumb-like distomedial process on labial palp segment 2, a proximal arc of setae on the tibiae, two enlarged subapical denticles in the tarsal claws, and seven gill pairs with posteriorly oriented tracheae and anterodistal marginal serration. Adults are distinguished by possessing hindwings with two longitudinal veins and an elongate, acute costal process, and a robust segment 3 of the male genital'forceps. The larval stage of $C$. flava is redescribed, and new figures are provided to illustrate previously overlooked characters.

Crassabwa : un genre nouveau d'Ephémères Pisciforma d'Afrique (Ephemeroptera : Baetidae)

Mots clés : Ephemeroptera, Baetidae, Crassabwa badia, C. flava, C. loweae, C. vitrea, genre nouveau, combinaisons nouvelles, Afrique.

Crassabwa Lugo-Ortiż \& McCafferty (Ephemeropteră': Baetidae), n. gen., est érigé pour un petit groupe monophylétique d'espèces Afrotropicales bien distinct, rangé antérieurement dans les genres Afroptilum Gillies et Centroptilum Eaton; il comprend C. badia (Kopelke), n. comb., C. flava (Crass), n. comb. (type species), C. loweae (Kimmins), n. comb., et $C$. vitrea (Navás), n. comb. Les larves de Crassabwa se distinguent par la présence : d'une protubérance distale interne en forme de poưce sur le segment 2 du palpe labial, d'un arc proximal de soies sur les tibias, de deux denticules subapicaux de grande taille aux griffes tarsales, et de sept paires de branchies à ramifications trachéennes orientées vers l'ätrière et à bord serratulé dans la région antérodistale. Les adultes se distinguent par leurs ailes postérieures portant deux nervures longitudinales et un processus costal allongé et aigu, et par leur robuste segment 3 des genitalia mầles. La larve de $C$. flava est redécrite, et des caractères passés inaperçus jusqu'ici sont illustrés.

\section{Introduction}

Gillies (1990) erected the genus Afroptilum (Ephemeroptera : Baetidae) to accommodate all African species previously assigned to Centroptilum Eaton. He designated $A$; sudafricanum (Lestage) as the type species. Adults of Afroptilum were defined as having single marginal intercalaries in the forewings, hindwings present or absent in one or both sexes, a single or double costal spur in the hindwings when these are

\footnotetext{
1.. Department of Entomology, Purdue University, West Lafayette,
} IN 47907 USA. present, and "Baetis-like» genitalia. Larvae were defined as having glossae narrower than the paraglossae, tarsal claws edentate or with one or two rows of denticles, asymmetrical gill lamellae, and terga 8 and 9 .without posterolateral spines. Such characterization actually encompasses diverse evolutionary lineáges of baetids, and Afroptilum has thus been considered polyphyletic (McCafferty \& de Moor1995, Barber-James $\& \mathrm{McCafferty}$, in manuscript). The different generic lineages represented by Afroptilum s. auctt. have begun to be sorted out (Wuillot \& Gillies 1994, McCafferty \& de Moor 1995; Barber-James \& McCafferty, in manuscript).

As part of:our revision of Southern. Hemisphere Baetidae, we have become engaged in an intensive survey 
of the baetid fauna of Africa to evaluate its systematic status and determine its biogeographic and phylogenetic affinities. The necessity of such evaluations was pointed out by McCafferty \& de Moor (1995). In studying fresh material recently collected from South Africa by one of us (WPM), we found $A$. flavum (Crass), originally described under Centroptilum (Crass 1947), to represent a new genus distinct from Afroptilum. This discovery prompted us to review other African species. We further discovered that $A$. badium (Kopelke), A. loweae (Kimmins), and $A$. vitreum (Navás) are also referable to the new genus. Herein we describe and discuss the new genus and designate $A$. flavum as its type, which we redescribe in the larval stage to include important characterization not included in Crass's (1947) original description. All materials studied are housed in the Purdue Entomological Research Collection, West Lafayette, Indiana.

\section{Crassabwa Lugo-Ortiz \& McCafferty, n. gen.}

\subsection{Description}

Mature larva

$$
\text { - HEAD }
$$

Antennal scapes and pedicels bare. Frontal keel absent.

Labrum (Fig. 1) basally broad, with deep anteromedian cleft. Hypopharynx (Fig. 2) with apically pointed lingua and somewhat narrow superlinguae.

Mandibles (Figs. 3, 4) with incisors fused and prostheca apically denticulate. Right mandible (Fig. 4) with tufts of setae between prostheca and mola and at base of mola.

Maxillae (Fig. 5) with two-segmented palps, extending as far as galealaciniae; segment 2 apically pointed.

Labium (Fig. 6) with three-segmented palps; palp segment 1 as long as segments 2 and 3 combined; palp segment 2 with thumb-like distomedial process; segment 3 somewhat elongate, apically rounded; glossae basally broad, apically pointed, subequal to paraglossae; paraglossae narrow, apically pointed.

\section{-THORAX}

Hindwingpads present.

Legs (Fig. 7) without villopore; dorsal and ventral margins of femora subparallel; tibiae with small proximal arc of long, fine setae; tarsal claws (Fig. 8) with two enlarged subapical denticles and four to six small basal denticles.

\section{-ABDOMEN}

Tergal surfaces (Fig. 9) with scale bases and sharp triangular spination on posterior margin.

Gills (Fig. 10) on abdominal segments 1-7, plate-like, anteriorly serrate near distal end (Fig. 11), branches of tracheae posteriorly oriented.

Paraproct as in Figure 12.

Three caudal filaments present; terminal filament subequal to cerci.

Adult

-HEAD

Male turbinate eyes mounted on short stalks.

-THORAX

Forewings [Crass (1947) : Fig. 20d] with single marginal intercalaries. Hindwings [Crass (1947) : Fig. 20f] elongate; with acute costal process and two longitudinal veins, sometimes not reaching wing margin.

\section{-ABDOMEN}

Genitalia [Crass (1947) : Fig. 20e] with three-segmented forceps; segment 1 cylindrical; segment 2 elongate, basally broad; segment 3 ellipsoidal.

\subsection{Etymology}

We name this genus after $\mathrm{R}$. S. Crass, in recognition of his extensive pioneering studies on South African Ephemeroptera. The name is feminine, and it consists of an arbitrary combination of letters incorporating Crass's name.

\subsection{Type species \\ Centroptilum flavum Crass, 1947 : 78.}

\subsection{Included species}

Crassabwa badia (Kopelke), n. comb. ; C. flava (Crass), n. comb. ; C. loweae (Kimmins), n. comb. ; $C$. vitrea (Navás), n. comb.

\subsection{Distribution}

Malawi ; South Africa : Kwazulu-Natal, Mpumalanga, Northern Province ; Tanzania ; Uganda ; Zaire.

\subsection{Discussion}

In our study of species assigned to Afroptilum, we have used $A$. sudafricanum as representative of true Afroptilum for comparative purposes. Thus, larvae of Crassabwa are distinguished by the thumb-like distomedial process of the second segment of the labial palps (Fig. 6), the proximal arc of setae on the tibiae (Fig. 7), the two enlarged subapical denticles in the tarsal claws (Fig. 8), and the seven gill pairs possessing 

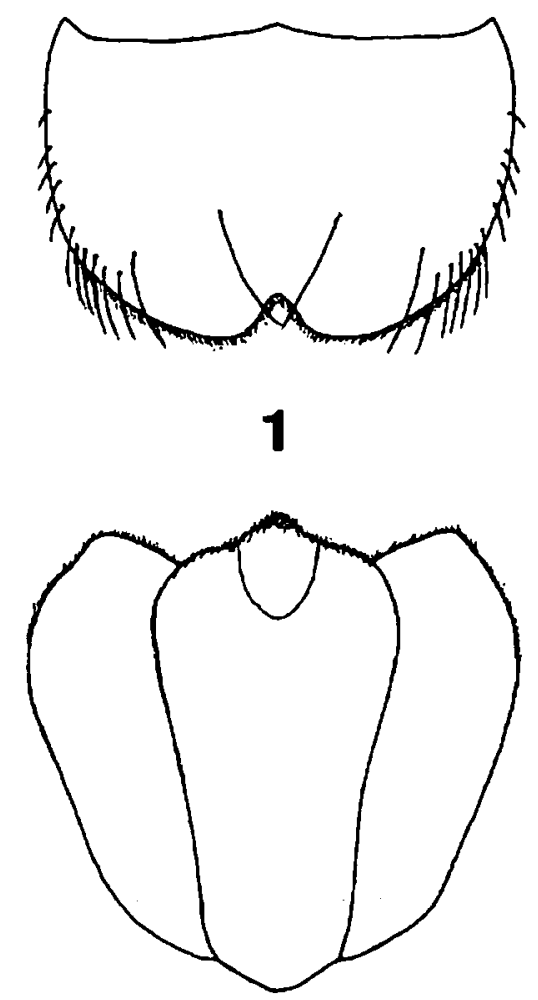

2
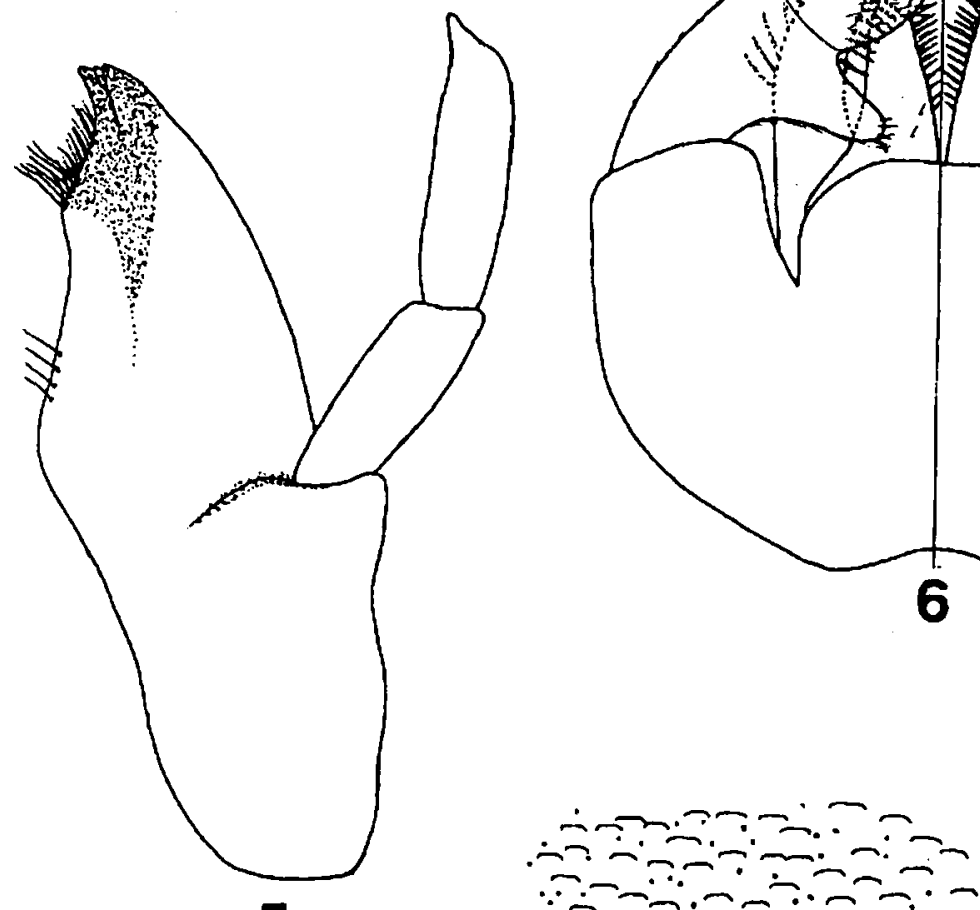

5

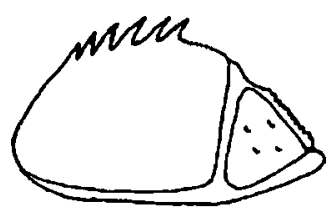

12

Viñnini

9
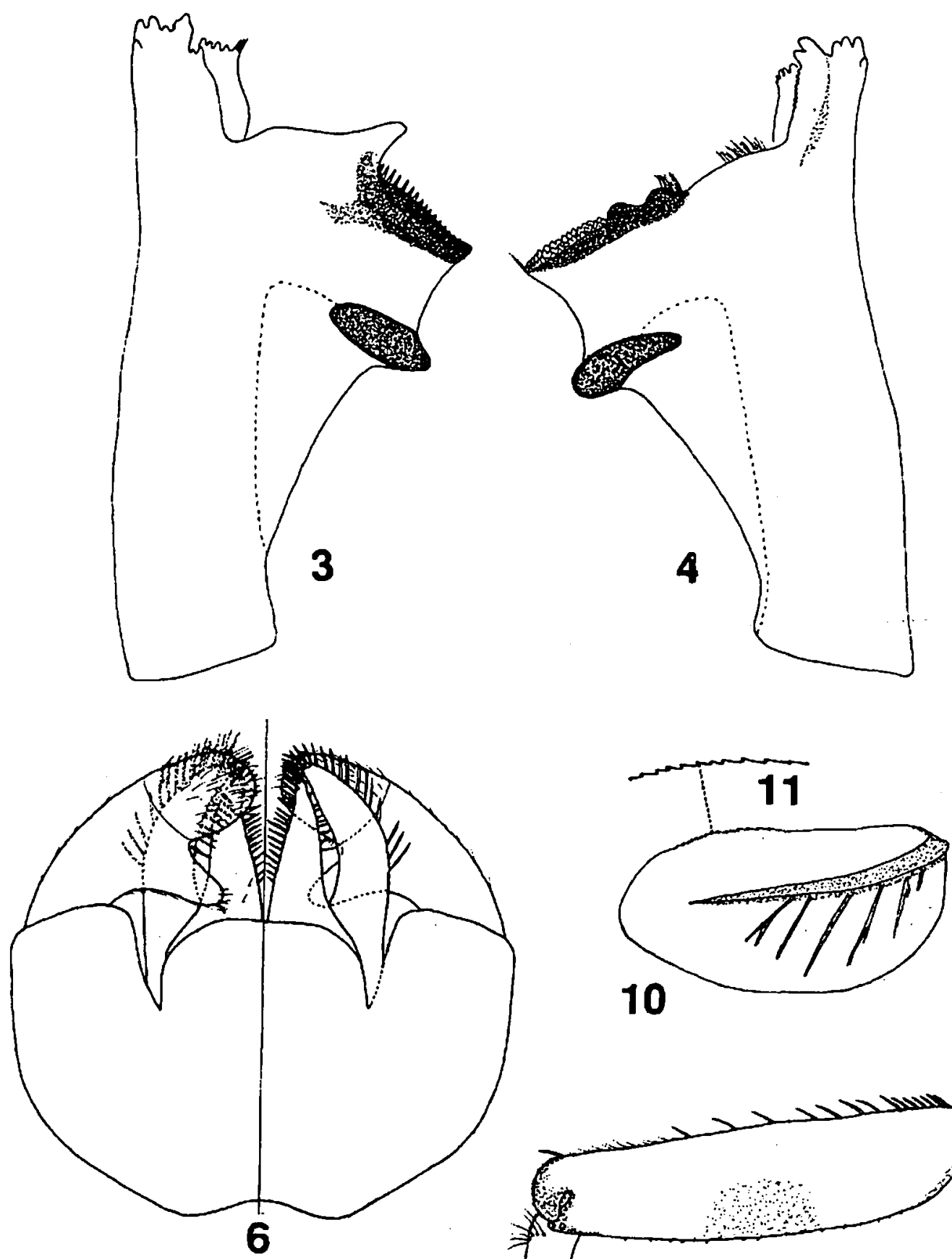

10

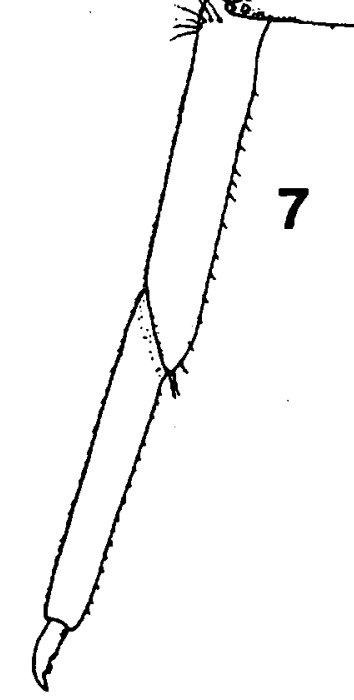

Figs. 1-12. Larval structures of Crassabwa flava (Crass). $1:$ labrum (dorsal view). $2:$ hypopharynx. $3:$ left mandible. $4:$ right mandible. $5:$ left maxilla. 6 : labium (left : ventral view ; right : dorsal view). $7:$ right foreleg. $8:$ tarsal claw. $9:$ detail of hind margin of tergum $4.10:$ gill 4 . 11 : detail of gill margin. 12 : paraproct.

Figs. 1-12. Structures larvaires de Crassabwa flava (Crass). 1 : labre (vue dorsale). $2:$ hypopharynx. $3:$ mandibule gauche. $4:$ mandibule droite. $5:$ maxille gauche. $6:$ labium (à gauche : vue ventrale ; à droite : vue dorsale). $7:$ patte antérieure droite. $8:$ griffe tarsale. $9:$ détail de la surface du $4^{c}$ tergite. $10: 4^{c}$ branchie. $11:$ détail de la surface de la $4^{*}$ branchie près du bord postérieur. $12:$ paraprocte. 
posteriorly oriented tracheae and anterodistal marginal serration only (Figs: 10, 11). Adults are distinguished by the two longitudinal veins and elongate, acute costal process of the hindwings [Crass (1947) : Fig. 20f] and the more robust segment 3 of the male genital forceps [Crass (1947) : Fig. 20e].

Phylogenetic relationships of Crassabwa are difficult to ascertain at this moment because of the present dearth of information on the biodiversity of baetids in the Southern Hemisphere. On the basis of the relatively narrow glossae and paraglossae (Fig. 6), presence of proximal arc of setae on the tibiae (Fig. 7), tergal armature (Fig. 9), and general gill morphology (Figs. 10, 11), Crassabwa preliminarily appears to be related to the Pantropical genus Cloeodes Traver. However, adults of Cloeodes have some double marginal intercalaries in the forewings (although there is a tendency in some species to loose one of the intercalaries in some marginal interspaces), and their hindwings, when present, have a basally broad costal process located in the middle (Waltz \& McCafferty, 1987). Additionally, the second segment of the male genital forceps has a distinct, setose basal bulge that Crassabwa lacks (Waltz \& McCafferty, 1987).

\subsection{Crassabwa badia (Kopelke), n. comb.}

Centroptilum badium Kopelke, 1980: 113.

Afroptilum badium (Kopelke) : Gillies, 1990 : 99.

Kopelke (1980) described C. badia based on male and female ádults collected from Zaire. Gillies (1990) transferred the species to Afroptilum, but did not state the reasons for this transfer. The morphology of the male genitalia [Kopelke (1980) : Fig. 21a] and male and female hindwings [Kopelke (1980): Figs. 22b, c, d] agree with our concept of Crassabwa, and on this basis we transfer Kopelke's species to the new genus.

\subsection{Crassabwa flava (Crass), n. comb.}

Centroptilum flavum Crass, 1947 : 78.

Afroptilum flavum (Crass) : Gillies, 1990 : 99.

\subsubsection{Description}

Mature larva

Body length : 7.5-8.5 mm; caudal filaments length : 2.7-3.0 mm.

\section{- HEAD}

Coloration medium brown, with vermiform cream markings on vertex and cream below median ocellus.

Antennae nearly $2.5 x$ length of head capsule.

Labrum (Fig...1) with one elongate, fine, simple submedian seta and eight to nine elongate, fine; simple submarginal setae on either side of midline. Hypopharynx as in Figure 2.

Left mandible (Fig. 3) incisors with six to seven denticles, enlarged denticle in midregion. Right mandible (Fig. 4) incisors with six large denticles and row of minute denticles on medial margin..

Maxillae (Fig. 5) with four denticles on galealaciniae and four long, simple setae near medial hump.

Labium (Fig. 6) with relatively long, simple setae marginally; palp segment 2 without dorsal setae; palp segment 3 with many short, fine simple setae.

\section{-THORAX}

Coloration yellow-brown; with pale yellow-brown markings:

Legs (Fig. 7) pale yellow-brown; femora with medium brown medial mark and medium to dark brown proximally and distally, and with 12-14 simple setae of medium length dorsally and scattered short, stout, simple setae ventrally; tibiae cream, occasionally medium brown proximally and distally, with minute short, simple setae dorsally and scattered short, stout, simple setae ventrally; tarsi cream, occasionally medium brown proximally and distally, with minute short, simple setae dorsally and scattered short, stout, simple setae ventrally; tarsal claws as in Figure 8.

\section{- ABDOMEN}

Coloration with complex and variable markings [Crass (1947) : Fig. 21a], usually with terga 1, 4, 7, and 8 paler than others.

Sterna cream to pale yellow-brown.

Tergal surfaces (Fig. 9) covered with scale bases; spines basal width nearly $0.5 x$ spines length.

Gills (Fig. 10) as long as two abdominal segments; marginal serration (Fig. 11) somewhat small.

Paraprocts (Fig. 12) dorsally bare, with five to six sharp marginal spines.

Caudal filaments cream to pale yellow-brown, with medial medium brown band.

Adult

Adequately described by Crass (1947).

\subsubsection{Material examined}

SOUTH AFRICA : Mpumalanga Province : Buffelspruit at Shalom (Aalwan), $4 \mathrm{~km} \mathrm{~W}$ of Badplaas paralleling Rt 38, off Avantune Rd, $1167 \mathrm{~m}, \mathrm{X}-17-1990$, P. and N. McCafferty, larvae ; Kruger Natl. Park, Sabie R at Sabie Gorge, Mozambique/South African border, X-22-1990, P. and N. McCafferty, larvae ; Kruger Natl. Park, Sabie R at Molondozi, X-231990, P. and N. McCafferty, exuviae and larvae; Kruger Natl. Park, Sabie R, below Measur. Wall, $9 \mathrm{~km} \mathrm{~N}$ of Zkukuza, X- 
24-1990, P. and N. McCafferty, larvae ; Kruger Natl. Park, Sabie R at Lisbon Estates, X-27-1990, P. and N. McCafferty, larvae ; Northern Province : Kruger Natl. Park, Olifảnts R, 15 km from blacktop rd, Fig Tree Site, X-29-1990, P. and N. McCafferty, larvae ; Kruger Natl. Park, Olifants R at.bridge on dirt rd, nr Olifants Camp, X-29-1990, P. and N. McCafferty, larvae.

\subsubsection{Discussion}

Crass (1947) described Crassabwa flava (as Centroptilum flavum) based on adults and associated larvae collected from Kwazulu-Natal. Later, Demoulin (1970) reported it from Uganda. Crass's (1947) description of the larvae is brief, and his figures are somewhat schematic. We have therefore redescribed the larval stage and provided new figures showing characters not indicated by Crass (1947).

The larval abdominal color pattern of $C$. flava is extremely variable, and it is of little diagnostic value for the species. The dorsal setation of the labrum (Fig. 1) is probably diagnostic, as is the denticulation of both mandibles (Figs. 3,4) and the spination of the paraprocts (Fig. 12). The mandibular figures by Crass (1947: 21f, g) give the impression that the incisors are cleft, and that the right mandible has an acute hump between the prostheca and mola. Close examination, however, revealed that the incisors are not cleft, and that the hump in the right mandible is more broadly based and attenuated. It additionally revealed the presence of minute denticles on the medial margin of the right mandibular incisors (Fig. 4). Our figures of the hypopharynx (Fig. 2) and left maxilla (Fig. 5) differ from those by Crass (1947 : Figs. 21e, d) in that we show the apically pointed lingua and second segment of the maxillary palps.

Crassabwa flava is possibly related to $C$. vitrea (Demoulin, 1957, 1970). However, $C$. vitrea is only known from female adults (see below), and until the larvae and male adults of that species are described, species relationships cannot be reliably determined.

Crass (1947) indicated that adults of $C$. flava emerge throughout the year, with a peak between March and May. However, Crass (1947) did not provide information on larval habitat. The larvae we studied were collected in abundance by WPM in a mid-sized stream four to seven meters broad at an altitude of $1167 \mathrm{~m}$, amongst cobblestones in shallow riffle areas. Water temperature was $16.2^{\circ} \mathrm{C}$ and the $\mathrm{pH}$ was 7.9 .

\subsection{Crassabwa loweae (Kimmins), n. comb.}

Centroptilum loweae Kimmins, 1948 : 829.

Afroptilum loweae (Kimmins) : Gillies, 1990 : 99.
Kimmins (1948) originally described $C$. loweae from male adults and male and female subimagos from Malawi. Later, Kimmins (1960) reported the species from Uganda and Tanzania, and redescribed the male adult and provided new figures of its genitalia. Gillies (1990) transferred the species to Afroptilum, but did not provide a rationale for that transfer. The hindwings [Kimmins (1948) : Figs. 1, 2] and male genitalia [Kimmins (1960) : Fig. 4b] agree with our concept of the male adult of Crassabwa, and on this basis we transfer the species to the new genus.

\subsection{Crassabwa vitrea (Navás), n. comb.}

Cloeon vitreum Navás, $1930: 322$. 262 .

Centroptilum vitreum (Navás) : Demoulin, 1957 :

\section{Afroptilum vitreum (Navás) : Gillies, 1990 : 99.}

Navás (1930) described this species from a single female specimen from Zaire. Demoulin (1957) redescribed the type specimen, provided figures of the foreand hindwings, and assigned the species to Centroptilum. Gillies (1990) transferred the species to Afroptilum, presumably based on Demoulin's (1957, 1970) comments that it was probably a variant of $C$. flavum. Although female adults in Baetidae are difficult to correctly assign to genera because of the virtual lack of reliable diagnostic morphological characteristics, we transfer this species to Crassabwa on the basis of its possession of an acute and elongate costal process in the hindwings [Demoulin (1957) : Fig. 3].

\section{Acknowledgments}

We thank H. Barber-James and F. de Moor (Grahamstown, South Africa) and N. McCafferty (West Lafayette, Indiana) for field assistance. We also thank A. Thomas (Toulouse, France) for assisting in the preparation of the manuscript. Research funds were provided to the second author by the South African Foundation for Research Development and the Anglo-American and de Beers Chairman's Fund. The Albany Museum kindly provided office and laboratory facilities to the second author during his stay in South Africa. This paper has been assigned Purdue Agricultural Research Program Journal No. 15142.

\section{References}

Crass R.S. 1947. - The may-flies (Ephemeroptera) of Natal and the Eastern Cape. Ann. Natal Mus., 11 : 37-110.

Demoulin G. 1957. - Revision de quelques éphéméroptères décrits du Congo Belge par L. Navás. III. Bull. Ann. Roy. Entomol. Belg., $93: 257-275$.

Demoulin G. 1970. - Ephemeroptera des faunes éthiopienne et malgache. p. 24-170. In: South African Animal Life, Results of the Lund University Expedition in 1950-1951. 14. Stockholm.

Gillies M.T. 1990. - A revision of the African species of Centroptilum Eaton (Baetidae, Ephemeroptera). Aquat. Insects, 12 : 97. 128. 
Kimmins D.E. 1948. - Ephemeroptera from Nyasaland, with descriptions of new species. Ann. Mag. Nat. Hist.; Ser. 12, $1: 825$ 836.

Kimmins D.E. 1960. - Notes on east African Ephemeroptera, with descriptions of new species. Bull. Brit. Mus. Nat. Hist. Entomol. $9: 339-355$

Kopelke J.-P. 1980. - Ephemeroptera aus der Emergenz des zentralafrikanischen Bergbaches Kalengo (Zaïre). Entomol. Abhdl. Staat. Mus. Tier. Dresden, $43: 99-129$.

McCafferty W.P. \& de Moor F.C. 1995. - South African Ephemeroptera : problems and priorities. p. 463-476. In: L. Corkum \& J. Ciborowski (eds.), Current directions in research on Ephemeroptera. Canadian Scholars' Press, Toronto.
Navás L. 1930. - Insectes du Congo Belge. Rev. Zool. Bot. Afr., 29 : 305-336

Waltz, R.D. \& McCafferty W.P. 1987. - Revision of the genus Cloeodes Traver (Ephemeroptera : Baetidae). Ann. Entomol. Soc. Am., 80 : 191-207.

Wuillot J. \& Gillies M.T. 1994. - Dicentroptilum, a new genus of mayflies (Baetidae, Ephemeroptera) from Africa. Aquat. Insects, $16: 133-140$. 